\title{
NovOS RUMOS NA HISTÓRIA DA EDUCAÇÃO
}

\author{
Aula Magna proferida pelo Professor Gary \\ McCulloch, dA UNiversidade de Londres, NA UNinOVE \\ EM 18 DE ABRIL DE 2013
}

Tradução e notas:

Marisa Bittar Doutora em História Social (USP). Professora da Graduação e da Pós-Graduação em Educação da UFSCar. bittar@ufscar.br

É uma grande honra estar aqui hoje nesta grande cidade histórica e neste importante seminário. Sou muito grato aos nossos anfitrióes por me darem esta oportunidade, e pela maravilhosa hospitalidade, e muito feliz por encontrar velhos amigos.

Estou ansioso por contribuir com as atividades de vocês e conhecer mais sobre seu importante trabalho aqui no Brasil, que eu sei que é forte e se envolve com grandes tendências historiográficas.

Meu tema hoje consiste nos novos caminhos da história da educação. Eu pretendo olhar para o futuro do nosso campo e analisar novas tendências.

Até onde podemos apontar para novas direçóes e uma agenda de pesquisa vibrante e emergente que se engaja de forma crítica com perspectivas históricas, ideias, métodos e teorias?

E quão relevante é tudo isso para o Brasil e para o futuro da educação aqui nesta parte do mundo?

Naturalmente, eu não preciso lembrar a essa plateia que, para olhar para a frente nós precisamos primeiro de tudo compreender de onde viemos, e que para entender mudanças nós precisamos reconhecer continuidades.

Como Sol Cohen apontou em seu ensaio sobre a história da história da educação nos Estados Unidos, publicado há quase quarenta anos, essa abordagem não deve ser simplesmente sobre o preenchimento de um capítulo em falta na história da educação, mas deve procurar “[...] restaurar 
os links quebrados entre a nossa geraçáo e a dos nossos predecessores, para preencher algumas lacunas em nossa memória”.

Eu tentei ambas as coisas, olhar para a frente e para trás no meu livro A luta pela história da Educação. Um especialista descreveu o livro como parte historiográfico e parte currículo - e eu de fato suponho que nossas vidas e experiências estimulam nossas ideias e questóes sobre história numa perspectiva ampla.

Inicialmente, entáo, vou delinear alguns aspectos importantes nos quais a nossa história foi moldada para ser o que somos hoje como pesquisadores e professores neste campo, e as dimensóes dessa história que fornecem as fontes de nossas forças e das nossas fraquezas.

Vou descrever esta história em termos de uma luta, uma disputa sobre a natureza e propósito fundamental do campo, um campo que ainda não está resolvido e está no coraçâo dos dilemas sobre o nosso desenvolvimento futuro.

Essa luta está intimamente conectada ao nosso lócus intelectual como um campo de estudo, nas fronteiras da educação, história e ciências sociais, que nos oferecem ricos suportes para o nosso trabalho, mas que pode ser vulnerável a ataques.

Quero delinear algumas das nossas tradiçóes como um campo internacional para propor uma visão integrada que se envolve com todos esses constituintes ou tributários do nosso trabalho.

É notável, aliás, que, nos últimos anos, começou a haver, internacionalmente, uma abordagem mais consciente, aberta e reflexiva para tais questôes entre historiadores da educação internacional.

Essa abordagem também tem sido levada adiante, por exemplo, pelo historiador belga Marc Depaepe, como se pode ver na edição de seu trabalho publicado no final de 2or 2. Ele se refere a questóes gerais de historiografia, interpretação e método.

Mais recentemente ainda, Jesper Larsen, da Dinamarca, editou uma coleção internacional de ensaios intitulada Conhecimento, politica e história da educação. Eu contribuí com um ensaio para este volume, mas também há outros da Bélgica, Finlândia, França, Estados Unidos, América Latina, Alemanha e Noruega.

A contribuição de Marcelo Caruso sobre a América Latina, com foco na Argentina, em particular, assume um tom mais otimista do que as 
da Europa e da América do Norte, quando ele conclui que "[...] a disciplina é muito popular no campo de estudos educacionais, as posiçóes estão bem estabelecidas na estrutura universitária e o campo parece prometer que este estudo pode ser uma excelente preparação para outras carreiras".

Se for este o caso, pode ser um ponto de partida particularmente interessante para a nossa discussão hoje.

Isso nos leva a considerar algumas das abordagens promissoras para implementar a nossa pesquisa e reabastecer o nosso campo. Em um aspecto, isto implica em desenvolver as nossas conexôes com as teorias e métodos diferentes, e talvez mais fundamentalmente em reforçar nossas ideias sobre a teoria em si e os princípios metodológicos.

Isso envolve a busca de novos rumos em nosso trabalho, muitas vezes em áreas já familiares, mas encarando-as com uma nova perspectiva. E é essa busca de novidade, de frescor, de ousadia de olhar para a frente que é a questão-chave da minha conversa de hoje.

A história da educação é frequentemente considerada, pelo menos por recém-chegados, como um campo incontroverso e, talvez, pouco exigente de estudo, longe dos grandes debates do nosso tempo, talvez de preocupação marginal.

Ela poderia ser vista como fornecedora de um corpo razoavelmente estável de conhecimento que cresce organicamente ao longo do tempo, que está sempre conosco como uma presença familiar e talvez confortável.

No entanto, sob a sua plácida superfície encontramos um local de luta. Gostaria de caracterizá-lo como um campo excitante e intelectualmente desafiador de estudo que é altamente relevante para a compreensão de questóes mais amplas da história, educação e da sociedade como um todo.

Ele também é frequentemente propenso a debates ardentes sobre sua identidade e futuro como um campo. Na verdade, os debates sobre para o que ele serve e sobre a sua lógica e contribuição, já passaram pelo menos por todo o século passado.

E ainda é cercado por incertezas e inseguranças subjacentes.

Estas questôes sobre contestação, identidade, lógica e estratégia são tratadas de maneiras diferentes em países diferentes. Os problemas e oportunidades que enfrentam o campo podem ser muito diferentes se você está na Inglaterra, nos Estados Unidos, na Nova Zelândia ou no Brasil. Eles 
estão intimamente relacionados, em cada caso, às mais amplas questóes educacionais, sociais e políticas que afetam cada país.

E ainda assim eles têm raízes comuns, um patrimônio intelectual compartilhado que todos nós herdamos. Por muitos anos, como é bem sabido, a lógica dominante da história da educação foi a de apoiar o desenvolvimento dos sistemas nacionais de ensino que surgiram em todo o mundo nos séculos XIX e XX.

Suas principais tendências eram celebrar a propagação e crescimento da educação, para fazer proselitismo em nome da profissão docente, e sustentar avanços na reforma gradual e progressiva, apresentando-os como sintomas e estímulos de melhoria social e econômica gradual.

Foi isso que muitas vezes foi descrito como o modelo liberal-progressista da história da educação, um exercício acrítico de nostalgia e construção de mito, escrito principalmente por educadores para benefíciar a formação de professores. $\mathrm{O}$ valor histórico desse trabalho foi um pouco limitado, e acrescentou pouca bagagem aos métodos das ciências sociais e perspectivas, mas promoveu uma versão conveniente e útil do passado que professores, educadores e formuladores de políticas poderiam usar para apoiar seus próprios esforços.

Em outras palavras, ela tendia a ser altamente instrumental na natureza, construindo um passado útil para os interesses das instituições e políticas contemporâneas.

$\mathrm{Na}$ década de 1960, o modelo liberal-progressista estava sendo decisivamente minado, em parte porque era muito anti-histórico, mas também porque cada vez mais a sua narrativa otimista não soava verdadeira frente aos dilemas profundos da escolaridade ocidental.

Nos Estados Unidos, estudiosos, tais como Bernard Bailyn e Cremin Lawrence lideraram o caminho para questionar a orientação geral de escrita da história da educação; suas críticas ecoaram e se desenvolveram em outros países ocidentais durante as décadas seguintes.

Em seu lugar, nasceu uma lógica, uma alternativa rival que enfatizou as reivindicaçóes históricas do campo. De acordo com esta formulaçáo geral, a história da educação deve ser vista como um aspecto da história social, de tal forma que ela estaria preocupada principalmente com a descoberta das conexôes históricas entre a educação e outros aspectos da sociedade. 
$\mathrm{Na}$ Grã-Bretanha, este objetivo fundamental foi expresso com mais força talvez pelo historiador social Asa Briggs, escrevendo na primeira edição da revista História da Educação, quando argumentou que o estudo da história da educação deve ser considerado como parte do amplo estudo da história da sociedade: "[...] a história social amplamente interpretada com a política, a economia, e, é necessário acrescentar, a religião".

Uma implicação desta abordagem, pelo menos para alguns, foi a de que a história da educação deve se concentrar em sua missão de iluminar o passado para seu próprio bem, em vez de ficar contaminada com preocupaçóes sobre o presente.

Muitos historiadores da educação se consideravam ambas as coisas: historiadores e educadores. No entanto, na medida em que a história e a educação representavam lógicas concorrentes, o crescimento do ponto de vista histórico foi um desafio maior para a lógica que dependia principalmente do valor do campo para a educaçáo.

A terceira abordagem básica emanou das ciências sociais. Há muito tempo há contribuiçôes significativas para a história da educação de uma ampla gama de cientistas sociais. Na Grã-Bretanha, por exemplo, sociólogos como A. H. Halsey e Olive Banks produziram trabalhos históricos importantes, e mais amplamente as ideias de teóricos sociais, como Pierre Bourdieu, têm estimulado muitas novas abordagens.

No entanto, frequentemente há tensôes que se desenvolveram como resultado disso. Sociólogos e historiadores tenderam a ter um difícil relacionamento intelectual, os primeiros preocupados em desenvolver teoria e articular preocupaçóes metodológicas de uma forma que os historiadores muitas vezes acharam estranho e difícil.

O historiador cultural Peter Burke tem caracterizado a relação mútua entre historiadores e sociólogos como um "diálogo de surdos" em que "cada grupo tende a perceber o outro em termos de um estereótipo bastante grosseiro".

Essas tensões se refletiram na e em torno da história da educação. Houve também uma tensão emergente nas últimas duas décadas entre as análises amplamente sociais e científicas e as interdisciplinares, e outras justificativas estabelecidas para a história da educaçáo.

Alguns historiadores da educação afirmaram a contribuição histórica do campo, outros a sua importância educacional, outros as suas impli- 
caçôes para as ciências sociais de forma mais ampla. Tudo isso tem gerado pesquisa importante e interessante.

No entanto, eu gostaria de lembrar da grande tradição inclusa nessas chaves constituintes para resolver problemas que atravessam os três grandes domínios: educação, história e ciências sociais.

E, ao fazê-lo, eu me inspiro muito conscientemente no exemplo de duas grandes figuras do nosso passado.

O primeiro é Emile Durkheim; o segundo é Brian Simon.

Tanto Durkheim quanto Simon, de diferentes maneiras, enfatizaram a importância de cultivar a história da educação dentro de um quadro amplo, envolvendo educação, história e ciências sociais. Mais de um século atrás, Emile Durkheim, o sociólogo francês e professor de pedagogia na Sorbonne, em Paris, expressou uma visão ampla para a história da educação em suas aulas sobre a formação e desenvolvimento do ensino secundário na França.

Sua análise para o estudo da história da educação abrangia educação, história e ciências sociais. Durkheim argumentou eloquentemente que é soemente estudando cuidadosamente o passado que se pode antecipar o futuro e entender o presente, de modo que a história da educação oferece a mais sólida base para o estudo da teoria educacional.

A história também pode nos ajudar a entender a organização do ensino e iluminar os ideais educativos que foram projetados para serem alcançados, enquanto em termos mais amplos ela nos ajuda a compreender a própria humanidade e as aspiraçóes dos indivíduos e grupos.

O presente foi em si mesmo apenas "uma extrapolação do passado, do qual ele não pode ser cortado sem perder a maior parte do seu significado". Assim, ele insistiu:

- somente a história pode penetrar na superfície do sistema educacional atual;

- $\quad$ só a história pode analisá-lo;

- só a história pode mostrar-nos de que elementos ele é formado, de que condiçóes cada um deles depende, como eles estão inter-relacionados;

- só a história, em uma palavra, pode nos levar à longa cadeia de causas e efeitos de que ele é o resultado. 
Por essas razôes, de acordo com Durkheim, é que devemos realizar pesquisa histórica sobre a maneira pela qual as configuraçôes educacionais vêm progressivamente se agrupando, combinando e formando relaçóes orgânicas.

Ao mesmo tempo, Durkheim relacionou essas preocupaçôes sistematicamente com seus interesses sociológicos mais amplos. Ele argumentou que os estudos históricos e sociais eram "parentes próximos" que foram "destinados a se fundir um com o outro", e que a educação estava ligada a ambos.

Por exemplo, ele definiu a educação como a socialização metodológica da nova geração, pela qual a sociedade renovava-se a si mesma sob a supervisão do Estado.

Além disso, uma compreensão da psicologia também era necessária para compreender a diversidade da inteligência e do caráter humano.

Por sua parte, Brian Simon, o principal historiador da educação produzido na Grã-Bretanha desde a Segunda Guerra Mundial, insistiu que o estudo da história da educação deve ser destinado a iluminar a natureza da educação como uma função social, de importância primordial em qualquer sociedade.

De acordo com Simon,

[...] deve ser uma das principais tarefas do estudo histórico traçar o desenvolvimento da educação nesse sentido, para tentar avaliar a função que cumpriu em diferentes estágios de desenvolvimento social e, assim, chegar a uma compreensão mais profunda sobre a função que cumpre hoje.

O trabalho de Simon enfatizou as diferenças de interesses das classes sociais: "[...] os modernos sistemas de ensino, parece-me, são uma área na qual os interesses e objetivos de classes, estratos sociais e até mesmo grupos se encontram e muitas vezes se chocam".

Esta abordagem para a história da educação teve claras implicaçóes para a compreensão das políticas e problemas atuais. Ela deve, insistiu Simon, "[...] buscar os desenvolvimentos educacionais em perspectiva, e ao fazê-lo abrir os olhos dos professores para a verdadeira natureza de seu trabalho". 
Ela deve permitir que o aluno compreenda que as ideias educacionais e instituiçôes contêm componentes históricos, alguns dos quais podem não mais ser relevantes ou viáveis, e devem ser abertos à reconsideração, e concluiu celebremente: "Não há, talvez, nenhuma influência mais libertadora do que o conhecimento de que as coisas não foram sempre como são e não precisam continuar como são".

Quão relevante, então, são essas ideias, e os exemplos de Durkheim e de Simon, para os novos rumos na história da educação hoje? Pareceme que, nos últimos vinte anos tem havido desafios significativos para a história da educação em muitos países, ameaçando em muitos casos, a sua posição estratégica como um campo e seu potencial para o futuro.

Apesar do crescimento do papel ativo do Estado na educação, e do longo período de reforma educacional e reconstruçáo que tem sido generalizada ao longo desse tempo, os historiadores da educaçáo muitas vezes têm achado difícil fazer uma contribuição substancial para informar estas mudanças.

Mudanças na formação de professores e na natureza da pesquisa educacional têm levado a dificuldades estratégicas em diversos países.

No entanto, ao mesmo tempo, tem havido importantes avanços intelectuais no e em torno do campo, apontando o caminho para novos desenvolvimentos na teoria e metodologia, e, em algumas áreas-chave do nosso trabalho, eles estão gerando frutos em novos trabalhos significativos.

Pouco mais de dez anos atrás, o principal historiador americano da educação, Jurgen Herbst, que infelizmente faleceu muito recentemente, se queixou de que havia pouco ar fresco no campo, de modo que ficamos sempre repetindo mantras antigos.

Existem, ao mesmo tempo, pressóes concorrentes à especialização e demandas de balcão.

Mas parece-me, ao contrário dessas preocupaçóes, que o nosso campo agora está aprendendo, lenta, e por vezes dolorosamente, a recorrer a toda a gama de nossa herança intelectual.

Isso está nos ajudando a nos envolvermos de forma mais completa e aberta com abordagens teóricas e metodológicas da educação, da história e das ciências sociais.

E também está começando a haver um impacto significativo em áreas substantivas da nossa pesquisa. Isso é importante por razôes estratégicas bem 
como epistemológicas, pois buscamos maneiras de definir e defender a posição da história da educação na academia e no discurso público.

Mas encontrar formas de partilhar e valorizar as nossas preocupaçôes comuns como historiadores da educação é uma tarefa ideológica e pragmática fundamental de unir indivíduos e grupos cujo trabalho, por vezes, aparece como díspares e até mesmo incoerentes.

Isto é especialmente urgente em tempos difíceis como os que vivemos hoje, para tentar compreender a crise econômica e social em muitas sociedades contemporâneas, como parte de uma visão ampla e interdisciplinar para a história da educação como um todo.

Vamos olhar primeiro, então, para a relação entre o desenvolvimento da história da educação e a teoria e metodologia.

Uma característica interessante aqui é um desejo crescente por preocupaçôes teóricas de uma forma aberta e explícita.

A história da educação muitas vezes se sentiu desconfortável com a "teoria" em geral, não querendo ou não sendo capaz de se envolver com questôes teóricas e filosóficas, em comum com os historiadores em geral.

$\mathrm{Na}$ década de 1950, o sociólogo C. Wright Mills afirmou que, embora a história fosse por natureza teórica, muitos historiadores mostraram uma "calma desatenção" a isso que ele achou impressionante, mas inquietante.

Fritz Stern comentou uma vez que "[...] a maioria dos historiadores são relutantes em articular as suas opinióes com a teoria”.

No entanto, como Peter Burke reconheceu, em parte em resposta ao desafio do pós-modernismo, muitos historiadores superararam sua reticência profissional e têm refletido de forma mais amplamente sobre a relação geral entre história e teoria.

De acordo com Burke, isso levou a alguma convergência entre historiadores de um lado e teóricos de outro, numa "[...] época de linhas tênues e de fronteiras intelectuais abertas, uma época emocionante e confusa”.

$\mathrm{Na}$ história da educação, tem havido muito mais iniciativas na abordagem de debates teóricos ao longo dos últimos vinte anos.

Isso se refletiu em ediçóes especiais de revistas de história da educação para tratar de questóes teóricas e um emergente interesse nas implicações de percepções diversas como as de Quentin Skinner, Walter Benjamin, Edward Said, Stanley Liz e muitos outros. 
O desafio colocado pelo pós-modernismo tem sido especialmente forte na história da educação, onde uma tradição "empirista", baseada em "atos e fatos" se firmou e é difícil de desalojar.

No entanto, também aqui há um potencial movimento nos debates atuais sobre a natureza da verdade histórica, extraído da força de uma abordagem "social realista" do conhecimento, como propóe o trabalho recente de Michael Young.

Uma discussão epistemológica originada nas ciências sociais sobre as relações sociais do conhecimento tem implicaçóes importantes para a história da educação.

Em relação à metodologia, de forma semelhante, a história da educação tendeu a não ser consciente de questóes metodológicas familiares em outros campos, enquanto, geralmente, privilegiava uma narrativa elitista de mudanças políticas baseadas em relatórios e comitês do governo.

Isto teve como efeito a exclusão de vozes e pontos de vista de muitos, tais como meninas e mulheres, jovens da classe trabalhadora, minorias étnicas, grupos de imigrantes, e os povos indígenas em muitos países ao redor do mundo.

Novas fontes e métodos têm sido praticados em parte pelo arrola-

$[\ldots]$ tendeu a ser o modo de narrativa dominante de uma
Inglaterra vitoriana em que, talvez, a maior de todas as virtudes,
maior que o decoro sexual, era contar a verdade. Observando as

[...] tendeu a ser o modo de narrativa dominante de uma
Inglaterra vitoriana em que, talvez, a maior de todas as virtudes,
maior que o decoro sexual, era contar a verdade. Observando as

[...] tendeu a ser o modo de narrativa dominante de uma
Inglaterra vitoriana em que, talvez, a maior de todas as virtudes,
maior que o decoro sexual, era contar a verdade. Observando as mento de uma ampla gama de fontes documentais, bem como por meio de diferentes questionamentos sobre eles (as vozes silenciadas).

Documentos pessoais, como cartas, diários e autobiografias têm sido examinados com mais frequência e de forma sistemática.

Os romances são uma fonte, que têm sido de alguma maneira subaproveitados na história da educaçáo, embora eles forneçam um dos principais meios de transmitir as experiências subjetivas de escolaridade.

Um tipo de romance em particular, especialmente importante neste contexto, penso eu, é o romance realista do século XIX (por exemplo William Makepeace Thackeray, Vanity Fair; Charles Dickens, David Copperfield; George Eliot, Adam Bede), como também Madame Bovary, de Gustave Flaubert (I857), na França.

Charles Levine observou que o realismo 
coisas como elas são, com um distanciamento quase científico, ele substitui representaçôes falsas por autênticas, e força os leitores a se livrar de ilusôes que levam ao desastre moral.

Há muitos trabalhos mais recentes de ficção que fornecem interessantes evidências históricas, a partir de Adeus Mr. Chips, na década de 1930, tanto novelas quanto filmes, às peças de Alan Bennett em nossa própria época.

Fontes materiais de origem institucional, como manuais, revistas escolares, livros escolares e livros de registro têm sido usados mais amplamente.

Métodos biográficos têm investigado as relaçóes entre o pessoal e o privado, por um lado, e, por outro, o social e o político, ou aquilo que C. Wright Mills descreveu como a "imaginação sociológica”.

A história oral tornou-se uma característica comum do campo ao longo dos últimos vinte anos e isso foi seguido mais recentemente pela voga da história visual.

Esses instrumentos metodológicos permitiram atenção mais detalhada a ser dada para as experiências sociais de educação, inclusive da sala de aula, que até vinte anos atrás eram áreas proibidas para os historiadores da educação.

Um tema novo e promissor que deve tornar essa tendência ainda mais forte é o da história sensorial, que só agora está começando a ser reconhecida por sua potencial contribuição para a história da educação. Isso envolve valorizar os cinco sentidos: olfato, audição, tato, paladar e visão na pesquisa histórica.

A pesquisa histórica de Emily Cockayne sobre ambientes urbanos na Inglaterra, nos séculos XVII e XVIII ajudou a avançar o nosso entendimento sobre o que ela descreve como burburinho de sujeira, ruído e mau cheiro, uma gama diversificada de "[...] reaçôes físicas e emocionais para coisas desagradáveis, como má qualidade dos alimentos, fumo, sujeira, poeira, mau cheiro e putrefação".

A história sensorial e a história das emoçôes, porém, não têm sido utilizadas em grande extensão na história da educação, embora haja sinais de que esta situação esteja começando a mudar. 
Por exemplo, Burke e Grosvenor recentemente investigaram o "ouvir" da escola em termos de "uma exploração de som e audição na escola moderna", a "paisagem sonora" da escola no século XX.

Mark M. Smith sugeriu que há espaço para grandes iniciativas de novas pesquisas históricas sobre os mundos sensoriais das crianças, e como elas têm usado os sentidos no processo de aprendizagem dos protocolos sociais e expectativas culturais de sua sociedade.

Peter Hoffer indica que este procedimento tem sido aplicado para adultos, bem como para as crianças porque "eles entram no ambiente sensível para estar de acordo com as prioridades aprendidas de sensação”. Por exemplo, de acordo com Hoffer, a receptividade dos sentidos, ou a capacidade de descrever o que percebemos, pode ser expandida como experiência, para estabelecer uma "etiqueta sensível" em que os sentidos nos dizem onde nós pertencemos na sociedade e como devemos nos comportar em diferentes circunstâncias e contextos.

Como também indica Smith, foi o cheiro, talvez mais do que qualquer outro sentido, que serviu para criar e marcar território social, para identificar o "outro", para justificar diversas formas de subjugação e para servir como uma barreira contra a integração significativa nas sociedades hospedeiras ou dominantes.

A própria pesquisa de Smith sobre "raça" e escravidão na América do Sul no século XIX destaca vividamente a importância de "estereótipos sensoriais". Ele aponta também que os livros infantis, muitas vezes publicados no Norte, mas bastante lidos no Sul, "[...] lidaram com os sentidos em alguns detalhes e ensinaram às crianças o funcionamento fisiológico e cultural dos sentidos, o que por sua vez contribuiu para justificar uma dada ordem social".

Além disso, Smith relata esta dimensão sensorial para a resiliência da segregação escolar até o "Caso Brown" na década de I950, e conclui que, surpreendentemente, doravante

[...] os brancos não só têm de ver os negros, mas também ouvir, cheirar, sentir, e tocá-los, não mais do jeito que quiserem, mas nos termos estabelecidos pela autoridade federal e exigidos diariamente por pessoas negras. 
Tais desenvolvimentos teóricos e metodológicos, por sua vez, incentivaram novas abordagens em áreas-chave da história da educação, terrenos muitas vezes familiares, mas agora a ser tratados de forma diferente.

Um desses foi o tema de desigualdade e exclusão social. Trabalhos anteriores haviam enfatizado o conflito de classe social e o papel da classe trabalhadora organizada, como Brian Simon, na Grã-Bretanha, e Katz, nos Estados Unidos.

Um trabalho mais recente reflete uma ampla gama de problemas relacionados com a desigualdade e exclusão social, incluindo gênero, etnia, deficiência e sexualidade, e uma maior consciência do que é muitas vezes chamado de "interseccionalidade" destes problemas.

Em relação à classe social em si, um pouco da atenção deslocouse para a natureza das classes médias, em recentes pesquisas envolvendo historiadores e sociólogos. Alguns dos meus trabalhos recentes têm investigado as tradiçôes da classe média no ensino secundário da Inglaterra em termos de insegurança de status, medo do fracasso e ansiedade relacionados ao declínio social, neuroses familiares da burguesia.

Discussão histórica sobre a classe trabalhadora e a educação tem-se deslocado de uma preocupação com as dimensóes políticas e industriais para uma preocupação emergente com identidades culturais, por exemplo, como no excelente trabalho de Jonathan Rose, $A$ vida intelectual das classes trabalhadoras inglesas.

Histórias sobre o ensino igualmente tem mostrado uma tendência a se deslocar de uma preocupação predominante com a profissionalização nos anos de 1960 e sindicalismo na década de 1980 para um novo interesse pela natureza da profissão dos professores, isto é, a sua experiência cotidiana de ensino.

O trabalho de Kate Rousmaniere nos Estados Unidos e de Peter Cunningham e Phil Gardner na Inglaterra são excelentes exemplos dessa tendência recente, que tem sido muito estimulada pela história oral.

Ao mesmo tempo, houve uma nova consciência sobre a importância dos alunos e da aprendizagem na história da educação.

A história da alfabetização e da leitura tem procurado estudar cada vez mais a natureza dos leitores e do público e suas interaçóes com textos. Como Jonathan Rose observou: 
Vinte anos atrás, a historiografia sobre leitura mal existia. Muitos historiadores da época duvidavam que poderíamos captar algo tão particular, tão evanescente quanto as experiências íntimas de leitores comuns do passado. Onde estavam gravadas essas experiências? Que fontes poderíamos usar?

Mais amplamente, uma história social dos alunos e da aprendizagem pode ser seletivamente extraída da educação, história e ciências sociais de várias maneiras.

Primeiro, ela pode procurar se engajar teoricamente com o conceito de aprendizagem como um processo social mais completo e sistemático do que foi realizado em trabalhos históricos anteriores.

A aprendizagem não é simplesmente sobre a leitura, nem é medida simplesmente através da lógica dos propósitos sociais e das instituiçôes, e nem é meramente intelectual.

Como um processo social, ela engloba uma ampla gama de experiências por meio da qual o aluno passa a compreender a si mesmo e o mundo ao redor.

Segundo, esse processo é analisado do ponto de vista dos alunos, e não daquele dos dirigentes políticos e professores, como tem sido habitual.

Em terceiro lugar, é desenvolvida uma tentativa de relacionar esta história aos atuais problemas educacionais e políticos, e às tendências mais amplas de pesquisa em educação e as ciências sociais.

O objetivo geral de um trabalho como esse é começar a lançar luz sobre a natureza social e a importância do aprender desde que as ideias modernas sobre a aprendizagem começaram a ser desenvolvidas no Iluminismo do século XVIII.

Em termos de agendas internacionais e transnacionais, também há evidência de uma busca de novos rumos.

Muitas pesquisas sobre educação lidam com suas características como um aspecto da política social interna, enquanto um número menor destaca sua importância como parte da política e de questôes internacionais, especialmente no aspecto da exportação de ideias e práticas para outros países.

No entanto, há também uma outra dimensão que tem atraído atenção recentemente, que é a relação entre a mudança de posição dos países 
no cenário mundial e da natureza da educação e da sociedade local e nacional. Isto também diz respeito de forma ainda mais ampla a uma consciência da interdependência das naçóes e da natureza internacional e global de muitos desafios no mundo moderno.

A globalização ultimamente tem se tornado um tema emergente na história da educação, desde que autores como Richard Aldrich começaram a desenvolver perspectivas históricas sobre a educação e os desafios ambientais para a sobrevivência humana.

Neste contexto, cada vez mais atenção tem sido dada à história do Império Britânico e à natureza da sua contribuição e legado no mundo moderno. Grande parte desta literatura em geral, tal como os cinco volumes da História do Império Britânico (Oxford University), incluiu pouco material específico sobre educação.

Ao mesmo tempo, uma substancial literatura tem se desenvolvido também sobre as formas pelas quais as ideias e práticas de educação na Grã-Bretanha influenciaram o caráter da educação em diferentes partes do Império Britânico.

Esta literatura tem gerado debates interessantes em torno da natureza do imperialismo cultural, a relação entre "centro" e "periferia", em que medida as influências imperiais foram benéficas, e as maneiras pelas quais essas influências foram rejeitadas por diferentes áreas e naçôes.

Ultimamente, tem havido um crescente interesse nos tipos de resistência que se desenvolveram por parte de grupos colonizados e indígenas.

No entanto, as relaçóes educacionais entre a Grã-Bretanha e seu Império não funcionaram apenas em uma direção. Como Peter Burke apontou, há perigos evidentes em um modelo simples de "centro" e "periferia”, em que o conhecimento é difundido da Europa para outras partes do mundo, pois deve-se considerar uma abordagem que leve suficientemente em conta os "[...] fluxos de conhecimento da periferia para o centro, bem como na direcção oposta".

Durante a última década, tem-se desenvolvido um começo de interesse histórico no processo inverso, isto é, como as ideias e práticas de educação em diferentes partes do Império Britânico exerceram influência na sede do Império.

Esta nova literatura, estimulada em parte pelo livro de Edward Said, Cultura e Imperialismo, tem potencial para um grande trabalho de pesqui- 
sa mais profundo que investigue as dinâmicas da educação no Império Britânico, que raramente eram estáveis e muitas vezes imprevisíveis em sua natureza e efeitos.

O trabalho de Said considerou os "territórios que compartilham elementos em comum" e as "histórias entrelaçadas" da cultura imperial, examinando como "[...] uma atitude intelectual pós-imperial pode expandir uma comunidade que compartilha elementos em comum (ou comuns) entre a societade metropolitana e as anteriormente colonizadas".

Ele passou a investigar como as imagens do Império permearam a cultura ocidental, por exemplo, em grandes obras de ficção: "textos culturais importados da Europa de uma forma que muito claramente levam a marca da empresa imperial, de exploradores e etnógrafos, geólogos e geógrafos, comerciantes e soldados".

Esse insight-chave impulsionou uma nova literatura histórica focalizada na influência do Império em seus domínios.

$\mathrm{Na}$ medida em que as implicaçooes "para" e "da" educação estão em causa, alguns interessantes e importantes trabalhos anteriores também foram produzidos; por exemplo, os trabalhos de Castle e Heathorn sobre a identidade nacional e o currículo do ensino fundamental.

Essa tendência tem sido levada mais longe por Catherine Hall, cujo trabalho desenvolveu ligaçôes-chave entre a cultura metropolitana e o mundo imperial.

Hall e Rose têm ajudado a explorar uma série de maneiras em que o “[...] status da Grã-Bretanha como uma potência imperial se tornou parte das vidas vividas dos britânicos".

Hall se dedicou também à questão de como os processos formais de educação ajudaram a construir as visóes coloniais e expectativas dos colonizadores. O poderoso tema sobre "Impérios em casa" também foi discutido em detalhe em uma coleção que nasceu de um simpósio internacional promovido pela Sociedade de História da Educação (Reino Unido), realizado em Hamburgo, na Alemanha.

Nesta coleção, por exemplo, Ruth Watts investiga influências imperiais sobre a educação britânica no século XIX, com base na teoria pós-colonial e ampla literatura histórica, bem como em comparações com outros países imperiais. 
Para concluir, deixem-me finalmente refletir sobre alguns temas que se elevaram grandemente no meu pensamento para a palestra de hoje.

Primeiro, o tema da mudança.

Nosso campo mudou muito ao longo do século passado. Ele era então um lócus de textos duros, presunçosos, que mapearam o surgimento dos sistemas nacionais de ensino. Agora ele é diversificado, voltado para o exterior, intelectualmente revigorado pelo contato contínuo com os debates educacionais, históricos, sociais e científicos.

Ele deve continuar a mudar, a olhar para o futuro. Mas é preciso fazer isso de uma maneira coerente e com princípios e devemos fazê-lo através da compreensão de seu próprio passado, das continuidades e mudanças que nos trouxeram onde estamos hoje.

Em segundo lugar, o tema dos ideais.

A história da educação se preocupa com as aspiraçôes dos indivíduos e das famílias, das escolas e universidades, para melhorar a si mesmos e construir um futuro melhor. Estas esperanças e sonhos envolvem ideais, bem como interesses, ideais sociais que são testemunho das virtudes redentoras da humanidade. Vamos, como um campo, enquanto exploramos as contradiçóes da educação, descobri-lo em nós mesmos também, para recorrer a seus ideais, para aprendermos a nos construir sobre as nossas melhores tradiçôes e nossas melhores mentes.

Terceiro, o tema das parcerias.

A história da educação tem sido traçada ecleticamente sobre uma ampla gama de bases intelectuais que eu tenho caracterizado como educação, história e ciências sociais, e crescentemente, em um panorama internacional e global. Vamos considerar isso como uma parceria com interesses complementares, e não como uma relaçáo disfuncional de desiguais.

Em quarto lugar, o tema do futuro, para o qual eu acrescento um ponto de interrogação.

Como cantou Carly Simon ${ }^{1}$, nunca poderemos saber sobre os dias que virão, mas mesmo assim nós pensamos neles. Podemos levar adiante o grande projeto intelectual que os historiadores da educação enfrentam hoje em diferentes partes do mundo?

Se pudermos fazer isso, eu acredito que possamos ajudar a realizar, no século XXI, a grande visão estratégica da história da educação, tendo à frente a luta contínua pela história da educação, contribuindo para o 
surgimento de novas abordagens para estudo, de forma igual, da educação, da história e da sociedade, no espírito de Durkheim e Brian Simon, para um compromisso em igualdade de condiçóes que possa ser central e não marginal para uma ampla gama de estudiosos; e análises que nos digam mais sobre o nosso mundo em geral, e sobre nós mesmos.

Sáo Paulo, Uninove, I 8 de abril de 2013.

\section{Notas}

1 Em inglês, "Decisẫo Brown". Decorreu de uma açấo conhecida como "Brown versus Conselho de Educaçáo de Topeka (1954)" e talvez nenhum outro caso decidido pela Suprema Corte dos EUA no século XX tenha causado efeitos tão profundos. No final da Segunda Guerra Mundial, dramáticas mudanças nas relaçôes raciais americanas estavam acontecendo. Linda Brown, uma garota de oito anos de idade, havia sido recusada a frequentar uma escola elementar situada a apenas cinco quadras de sua casa em Topeka (Kansas). As escolas oficiais se recusaram a matriculá-la nas redondezas enviando-a a uma escola para alunos nấo brancos a vinte e uma quadras de sua casa. A família de Linda arguiu o Board of Education de Topeka. Por unanimidade $(9 \mathrm{x}$ 0 ) a Corte aceitou os argumentos da família de Linda Brown. Na sua primeira e provavelmente mais significativa decisão, o Chefe de Justiça Warren justificou: "Separar algumas crianças de outras da mesma idade simplesmente por causa de sua cor gera sentimento de inferioridade e pode afetar seus coraçôes e mentes de forma irreversível".

2 Carly Simon, premiada cantora norte-americana que começou a carreira cantando "folks" nos anos de 1960. A música citada é Anticipation (1971) e o verso é examente este: "We can never know about the days to come, but we think about them anyway".

Recebido em 26 out. 2013 / Aprovado em I9 nov. 2013

Para referenciar este texto

BITTAR, M. Novos rumos na história da educação. EccoS, São Paulo, n. 32, p. I2I-I38. set/dez. 2013. 